\title{
The Use of Scaffolds in Musculoskeletal Tissue Engineering
}

\author{
Frances Henson $^{1}$ and Alan Getgood ${ }^{*}, 2$ \\ ${ }^{I}$ Department of Veterinary Medicine, University of Cambridge, Cambridge, CB3 OES, UK \\ ${ }^{2}$ The Fowler Kennedy Sport Medicine Clinic, The University of Western Ontario, Ontario, Canada
}

\begin{abstract}
The use of bioengineering scaffolds remains an integral part of the tissue engineering concept. A significant amount of basic science and clinical research has been focused on the regeneration of musculoskeletal tissues including bone, articular cartilage, meniscus, ligament and tendon. This review aims to provide the reader with a summary of the principals of using material scaffolds in musculoskeletal tissue engineering applications and how these materials may eventually come to be incorporated in clinical practice.
\end{abstract}

Keywords: Musculoskeletal tissue engineering, scaffolds.

Tissue Engineering (TE) is the use of a combination of engineering, materials and cells to improve or replace biological functions. TE solutions are usually, but not always, based upon a scaffold (synthetic and/or biological), alone or in combination with precursor or specialist cell types and may include modifications such as the inclusion of bio molecules [1]. In recent years increasingly more complicated structures are being created and tested in the quest to find the 'ideal' analog to replace or encourage repair of the damaged tissue. The aim of this review is to provide an overview of the use of scaffolds in musculoskeletal TE.

\section{Which Musculoskeletal Tissue Repair Might Benefit From the Use of Scaffolds?}

Scaffolds can potentially enhance the repair or replacement of any of the tissues in the musculoskeletal system for a variety of reasons. Some of the tissues in the musculoskeletal system have a poor intrinsic repair capacity. For example, cartilage is notoriously poor at healing [2]; it has a slow rate of turnover and very limited capacity to repair defects. It is well recognized that partial thickness cartilage defects do not really heal at all, and that full thickness defects heal by recruitment of bone marrow derived stem cells from the underlying bone, often to form poor quality, disorganized fibrocartilage instead of the required hyaline cartilage [3]. However, even marrow progenitor cell recruitment can only heal osteochondral lesions up to critical sizes [4], beyond which defects in the articular surface remain. Scaffolds might therefore represent an excellent strategy to assist healing of both chondral and osteochondral lesions.

Tendons, menisci and ligaments are also considered to have relatively poor healing compared to most tissue types [5], although their healing is not as poor as cartilage. Similar also to cartilage, damaged tendon and ligament is often repaired by disorganized, weaker tissue which is prone to re-

*Address correspondence to this author at the Fowler Kennedy Sport Medicine Clinic, The University of Western Ontario, Ontario, Canada;

Tel: +1 (0) 4036 097286; Fax: +1 (0) 4036 097285;

E-mail: agetgood@btinternet.com injury [6] and the use of scaffolds to promote more functionally appropriate healing would be highly advantageous.

In contrast to these tissues, bone and muscle have excellent healing capacities and are usually able to achieve an effective repair [7]. However, in some circumstances even these tissues are not able to completely repair. For example, bone repair can be poor for a number of reasons resulting in delayed and non unions [8]. In large defects created during the treatment of bone or muscle neoplasia there may simply be too big a physical gap for normal healing to bridge [7]. In each of these clinical challenging scenarios, scaffolds represent an excellent strategy to assist healing by providing a support structure for cells, a source of cells and/or biological factors or a combination of all of these.

\section{What Makes a Good Scaffold?}

Scaffolds designed for use in musculoskeletal TE should meet several criteria [9] including:

1. They should be biodegradable and biocompatible the scaffolds must be able to be absorbed by the tissue once the functional life of the scaffold is reached or integrated into the tissue.

2. The scaffold should not promote and inflammatory or immune response in the tissue.

3. The scaffold surface and porosity should permit cell adhesion and growth and permit the expression of the appropriate cellular phenotype.

4. The material should have the mechanical properties required to withstand the biological demands made upon it during the reparative period.

5. The material must be able to be produced reproducibly.

6. The scaffold must be able to be supplied sterile, in an appropriate size for surgical placement.

7. The scaffold should have good handling properties i.e. are able to be trimmed to fit defects and be amenable to manipulation with surgical instruments. 


\section{EVALUATION OF SCAFFOLDS}

Many different scaffolds exist, at all stages of development from initial material description through to completed clinical trials. Given the rapidly expanding literature in this area, how can the clinician objectively evaluate the data that is generated from the testing of potential scaffolds? The development and use of a scaffold intended for TE falls into four broad categories; the production of the scaffold material itself, in vitro biocompatibility testing, pre-clinical trials in animal models (small and large animal [10]) and human clinical trials. Thus, at any one time scaffolds are at different stages of the evaluation procedure, making it difficult to compare the effectiveness of any given scaffold against its 'competitors' (i.e. scaffolds of different structure intended eventually for the same clinical use). In truth, a scaffold can only ever be fully evaluated at the end of a significant number of patient treatments and all intermediate data, while of interest, is merely a guide to potential performance in vivo.

\section{Materials}

The most common and simple scaffolds that have been used for decades are patients own tissue (auto graft) or cadaveric donor tissue (allograft). Autograft such as hamstring tendons or the patella tendon have been incorporated in anterior cruciate ligament reconstruction since the 1960's. [11]. Studies have shown host tissue infiltration (ligamentization) by approximately 12 weeks [12]. Similarly allograft has also been used for the same purpose, often taking slightly longer to incorporate. The treatment of bone fracture non-union has been treated extensively with bone autograft, often being harvested from the iliac crest. Not only does this scaffold provides structural osteoconductive support, but also lends itself to having osteoinductive and osteogenic properties. However, donor site morbidity has led many clinicians to use allograft which, due to its processing and storage, only have osteoconductive properties [13]. As a result, in the past two decades a great emphasis has been placed on the production of 'off the shelf' scaffolds' which can be used to treat bone, but also ligament, tendon and cartilage.

Some of the earliest well described scaffolds were made of relatively simple synthetic materials, for example polyethylene meshes [14, 15], carbon implants [16] or carbon-polylactic acid (CPA) polymers [17-19]. However, since these early materials were used, there has been much development of biologic and synthetic materials and combinations thereof.

Biological scaffolds may be classified as to the predominant type of material used e.g. protein or carbohydrate. The most common protein derived scaffolds are those made from collagen. Examples include Matrix Assisted Chondrocyte Implantation (MACI, Genzyme Inc., Oxford, UK) which utilizes a collagen type I/III scaffold/membrane to culture chondrocytes ex-vivo prior to implantation into an articular cartilage defect [20]. Whilst the use of collagen alone as a scaffold has been shown to be a successful strategy, collagen has also been successfully combined with other biological materials to form commercially available tissue repair systems. The addition of a ceramic such as calcium phosphate has been used in a number of osteochondral scaffolds including Chondromimetic (Tigenix, Cambridge, UK) and Maioregen (Finceramica, Italy). The ceramic alone can be used as a scaffold, such as porous Hydroxyapatite as a bone graft substitute (Apapore, Baxter Healthcare, Deerfield IL). This has been in a number of clinical trials with satisfactory outcome [21]. Other naturally occurring substances in cartilage have been added to collagen to help mimic the extracellular matrix, such as chondroitin sulphate in the Novocart 3D (Tetec, Germany) in which autologous chondrocytes are combined with a 3D collagen/chondroitin sulphate scaffold.

Carbohydrate based scaffolds include hyaluronic acid, which has been incorporated in Hyalograft C (Hyaff-11, Fida Advanced Biopolymers, Abano Terme, Italy). This is another naturally occurring material in cartilage and therefore represents a biological treatment option. The BSTCargel system (Bio-Syntec Inc., Canada) utilizes a chitosan based scaffold infused with uncoagulated whole blood prior to implantation into a microfracture lesion [22]. Chondron (Sewon Cellontech, Korea) is a commercially available fibrin gel based autologous chondrocyte implantation device [23]. Fibrin has also been used as a tissue glue (Tisseel, Baxter, US), which has been used to form a biological scaffold to contain embryonic derived pluripotent cells and used to treat ovine osteochondral lesions [24].

Whilst biological materials are widely used as scaffolds in musculoskeletal TE synthetic materials are also well suited for use as scaffolds as they can be produced reproducibly, are relatively easily modified (both structurally and chemically) and have a minimal risk of provoking an immune response in the host. Since the development of the original synthetic scaffolds, a new generation of bioabsorbable synthetic materials have been investigated for their potential use as scaffolds. These new materials include polylactides, polyglycolides, polydioxanone, e-caprolactone, polycarbonates and their copolymers [25-32]. A number of synthetic musculoskeletal TE solutions are commercially available for use. In the Bioceed-C system (BioTissue, Germany), chondrocytes are seeded into a biodegradable polyglycolic/polylactic acid/polydioxanane based polymer fleece [33]. Scaffolds can also be used to support cartilage fragment implantation as well as cellular therapy. In a recently described cartilage autograft implantation system model, autologous cartilage fragments were added to a polydioxanone scaffold for implantation into chondral lesions [34]. In osteochondral lesion repair the use of the Trufit (Smith and Nephew Endoscopy, Andover, MA) plug (a multiphasic implant consisting of polyglycolic acid and poly-D-L-lactic-co-glycolide fibres plus $10 \%$ calcium) has produced good clinical results over reasonably extended recovery timescales in patients [35] and a polyurethane meniscal scaffold has shown promising results as a meniscal replacement in pre-clinical trials (Actifit, Orteq, US) [36] and in a more recent clinical study [37].

In addition to these synthetic and biological scaffold developments, a number of synthetic/biological composite scaffolds have been developed, such as bioglass-collagenphosphatidylserine scaffolds [38], collagen/PLA composites [39] and bioactive glass/polycaprolactone/biphasic calcium phosphate scaffolds [40], many of which are in the earliest 
stages of biocompatibility testing and on whom relatively little data is currently available for evaluation. However, one hybrid scaffold, Osseofit, (Kensey Nash Corporation, USA) is commercially available for use as a bone void filler model in pre-clinical trials [9]. This biphasic scaffold is composed of a type I collagen chondral layer and a beta tricalcium phosphate ceramic suspended in a polylactic acid lattice.

\section{Biocompatibility Testing}

Once a material has been identified suitable for a scaffold then biocompatibility testing (testing the ability of the scaffold to support cell growth and function in vitro) is undertaken. The majority of scaffolds are, at some point in their development, assessed for their ability to support the growth of multipotential cells. The most commonly described cell type grown on scaffolds for musculoskeletal TE is the mesenchymal stem/progenitor cell (MSC), which may be harvested from many musculoskeletal tissues but most commonly from bone marrow [41-43]. More recently, MSC's have been sourced from human embryonic stem cells [44]. MSCs can differentiate into any of the cell types of the musculoskeletal system when induced by the appropriate in vitro or in vivo cues $[43,45]$ - the ability of the scaffold to support cells that can become any of the differentiated cells of the musculoskeletal systems may indicate the broad potential of the scaffold as a cellular support.

More specific biocompatibility testing examines to what extent the scaffold can support the differentiated cell type that it is intended to 'host' in vivo. Thus in simple experimental systems meniscal scaffolds are tested with fibroblasts of meniscal origin [46, 47], chondral scaffolds with chondrocytes [48-50], tendon scaffolds with tenocytes $[51,52]$ and so on. However, single cell experiments, whilst informative, do have their limitations. The musculoskeletal tissues are complex. They may be multicellular, containing specialized niches (bone [53]) or composed of cellular subtypes with different properties (cartilage) [54, 55]. They all have inter-tissue regional variations of mechanical stresses and strains, extracellular matrix components and other tissue interfaces [56], which a single cell experiment does not replicate. Thus more complicated biocompatibility assays are devised to test the efficacy of a scaffold. For example, seeding chondrocytes and fibroblasts inside and outside a meniscal scaffold [57]; seeding osteoblasts and fibroblasts onto a ligamentous scaffold [58]; seeding osteoblasts/ endothelial cells on DegraPol (AbMedica, Italy) foam scaffolds in a chick chorioallantoic bone graft model [59]; and, in a highly complex series of experimental steps, seeding chondrocytes, osteoblasts and fibroblasts onto a single scaffold in order to provide the cell types required to fully heal an anterior cruciate ligament (ACL) rupture [58, 60-62]. Assessing how cells behave in these different experimental systems allows judgements to be made as to their suitability for use in musculoskeletal TE. Clearly scaffolds that support the biological functions of the cells that they are intended to 'host' in vivo are the most likely candidates to progress through to further assessment. However, there is a danger that TE solutions that become too complicated become difficult to manage in a clinical setting and too expensive for routine use.

\section{Pre-Clinical/Animal Model Testing}

Evaluating the effectiveness of scaffolds in the treatment of musculoskeletal pre-clinical problems is difficult, as, despite the large number of in vivo and in vitro models described in the literature, no 'industry standard' models have yet been adopted within which systems can be tested [63]. In addition to the wide variety of models available in which to test a scaffold, multiple confounding factors affect the interpretation of results. For example, the age of the test subject and of tissue donors [64, 65]; different natural healing rates in similar structures e.g. the ACL heals poorly following damage compared to the medial collateral ligament (MCL) [66]; differences in natural healing biology in, for example full thickness cartilage defects (good healing) compared to partial thickness defects (poor healing) $[67,68]$.

When considering pre-clinical models of musculoskeletal damage/repair one must question which is the ideal model to replicate the human situation [63]. An example of the difficulties encountered when choosing an optimal animal model to test a TE scaffold based solution is in the treatment of osteochondral defects. Lesions in the distal femoral condyle of the knee ('stifle') are probably the most commonly used model defect in pre-clinical osteochondral scaffold studies but the thickness of the cartilage at this site, compared to man, varies considerably between species. In man the distal femoral cartilage is reported to be $2.2 \mathrm{~mm}$ in depth with $2 \%$ chondrocyte volume density (CVD); of the commonly used species in pre-clinical studies the horse is most similar to man (2mm depth, 6-7\% CVD) with the rabbit (a very commonly used pre-clinical study species) being very dissimilar $(0.2-0.4 \mathrm{~mm}$ depth, 2-12\% CVD) [63]. However, whilst equine cartilage can be considered the most similar to human, preclinical equine studies are expensive, specialist and subject to strict welfare controls. Thus many research groups use smaller 'large animals' such as sheep, goat and pigs, which are easier and cheaper to source and maintain to assess scaffold performance in vivo. However, many scaffolds are evaluated in vivo in small animal models, particularly rabbits and rodents. There are significant complications in the interpretation of results in these species. Rodents are fundamentally different from large animal and human cartilage in that they do not close their growth plates even at maturity and thus have very different chondrocyte subpopulations compared to large animals/humans. Indeed rodent and rabbit cartilage defects naturally heal very rapidly and thus the results of scaffold performance in these animals must be considered in light of these differences - any scaffold in these species will perform well.

\section{Clinical Trials}

TE scaffold based solutions that are demonstrated to have positive effects on repair and regeneration both in vitro and in pre-clinical trial are then often taken forward into clinical (patient) trials. However, given the relative novelty of this field of research, there is a paucity of information currently available on the performance of TE scaffold based solutions. Once again, difficulties arise as there is currently no 'gold standard' for the evaluation of tissue repair. For example, in chondral and osteochondral repair a number of techniques to 
evaluate tissue repair have been described by research and clinical groups worldwide. These techniques use a variety of scoring systems including radiographic/MRI, second-look arthroscopy and clinical outcome measures. At the current time, these evaluation techniques show that many of the scaffold based repair systems in commercial use have efficacy for the treatment of cartilage lesions in the short and medium term [23, 69], however there is little comparative data available.

\section{SCAFFOLDS OF THE FUTURE}

The development of scaffolds containing nanomaterials [70] is an interesting development in scaffold technology. Nanomaterials can mimic the architecture of the normal extracellular matrix (ECM) (which contains both nano and microfibers), which is likely to be very important in encouraging the cellular component of the TE construct to behave in a biologically appropriate fashion [71]. Nanofibers provide high surface area-to-volume ratios, increasing the contact area between cells and fibres and offering huge potential to deliver substances such as drugs [72] or growth factors [73] into an area of repair or regeneration [74]. However, the increased pore size and porosity of many nanofibres may lead to inferior mechanical properties compared to micro- or macro-fibres [75]. In order to address these concerns, further engineering of nanoparticle based scaffolds has been performed, for example aligning the nanofibres within the scaffold [76, 77] or producing nanofibre mats with programmed fibre direction [75]. These alterations have been shown to be beneficial to cellular growth and function in vitro and may be required to enhance their use in tissue regeneration. Just as nanofibres can be utilized to provide drug/protein delivery systems, other scaffolds can also be modified to further enhance their TE credentials. Scaffolds can be coated with growth factors such as fibroblastic growth factor-2 (FGF-2) [78, 79] and bone morphogenic proteins (BMPs) [79-81] with or without other bioactive molecules [82]. They can also be made more 'sticky' by, for example, coating them with the RGD (ArgGly-Asp) cell attachment site [83] to encourage the adhesion of the target cells. Possibly one of the most exciting developments is the design and production of selfassembling natural peptide nanofibre scaffolds that can be used alone or with other scaffolds to enhance tissue repair $[84,85]$. These nanofibre scaffolds can be genetically engineered to contain specific peptides designed specifically for the target tissue, for example, osteogenic growth protein and osteopontin cell adhesion motif for designer bone repair scaffolds [86].

\section{CONCLUSION}

Biological and synthetic based material scaffolds have an integral role in the potential application of musculoskeletal tissue engineering. As newer materials and technologies evolve, the pre-clinical testing will be of utmost importance before they can be utilized in widespread clinical use.

\section{ACKNOWLEDGEMENT}

None declared.

\section{CONFLICT OF INTEREST}

None declared.

\section{REFERENCES}

[1] Sahoo S, Toh SL, Goh JC. A bFGF-releasing silk/PLGA-based biohybrid scaffold for ligament/tendon tissue engineering using mesenchymal progenitor cells. Biomaterials 2010; 31: 2990-8.

[2] O'Driscoll SW. The healing and regeneration of articular cartilage. J Bone Jt Surg Br 1998; 80: 1795-812.

[3] Buckwalter JA. Articular cartilage injuries. Clin Orthop Relat Res 2002; 402: 21-37.

[4] Chu CR, Szczodry M, Bruno S. Animal models for cartilage regeneration and repair. Tissue Eng Part B Rev 2010; 16: 105-15.

[5] Forriol F. Growth factors in cartilage and meniscal repair. Injury 2009; 40(Suppl 3): S12-6.

[6] Molloy T, Wang Y, Murrell GAC. The roles of growth factors in tendon and ligament healing. Sports Med. 2003; 33: 381- 94.

[7] Pelled G, Atyelet B-A, Hock C, et al. Direct Gene Therapy for Bone Regeneration: Gene Delivery, Animal Models, and Outcome Measures. Tissue Eng Part B Rev 2010; 16: 13-20.

[8] Brown KV, Li B, Guda T, Perrien DS, Guelcher S, Wenke JC. Improving bone formation in a rat femur segmental defect by controlling BMP-2 release. Tissue Engineering Part A 2011.

[9] Getgood A, Brooks R, Fortier L, Rushton N. Articular cartilage tissue engineering: today's research, tomorrow's practice? J Bone Joint Surg Br 2009; 91: 565-76.

[10] Sah RL, Ratcliffe A. Translational models for musculoskeletal tissue engineering and regenerative medicine. Tissue Eng Part B Rev 2010; 16(1): 1-3.

[11] Tom JA, Rodeo SA. Soft tissue allografts for knee reconstruction in sports medicine. Clin Orthop Relat Res 2002; 402: 135-56.

[12] Gulotta LV, Rodeo SA. Biology of autograft and allograft healing in anterior cruciate ligament reconstruction. Clin Sports Med 2007; 26: 509-24.

[13] Innes JF, NMyint P. Demineralised bone matrix in veterinary orthopaedics: a review. Vet Comp Orthop Traumatol 2010; 23: 393-9.

[14] Parrish FF, Murray JA, Urquhart BA. The use of polyethylene mesh (Marlex) as an adjunct in reconstructive surgery of the extremities. Clin Orthop Relat Res 1978; (137): 276-86.

[15] Winston LA, Terry AF, Jardine JH, Parrish FF. The result of replacement of partial or total collateral ligaments with Marlex mesh in the knees of dogs. Clin Orthop Relat Res 1978; (137): 28790.

[16] Robinson D, Efrat M, Mendes DG, Halperin N, Nevo Z. Implants composed of carbon fiber mesh and bone-marrow-derived, chondrocyte-enriched cultures for joint surface reconstruction. Bull Hosp Jt Dis 1993; 53(1): 75-82.

[17] Alexander H, Weiss AB, Parsons JR. Absorbable polymerfilamentous carbon composites--a new class of tissue scaffolding materials. Aktuelle Probl Chir Orthop 1983; 26: 78-91.

[18] Aragona J, Parsons JR, Alexander H, Weiss AB. Soft tissue attachment of a filamentous carbon-absorbable polymer tendon and ligament replacement. Clin Orthop Relat Res 1981; (160): 268-78.

[19] Chvapil M, Speer DP, Holubec H, Chvapil TA, King DH. Collagen fibers as a temporary scaffold for replacement of ACL in goats. J Biomed Mater Res 1993; 27(3): 313-25.

[20] Bartlett W, Skinner JA, Gooding CR, Carrington RW, Flanagan AM, Briggs T. Autologous chondrocyte implantation versus matrix-induced autologous chondrocyte implantation for osteochondral defects of the knee: a prospective, randomised study. J Bone Jt Surg (British) 2005; 87: 640-5.

[21] McNamara I, Deshpande S, Porteous M. Impaction grafting of the acetabulum with a mixture of frozen, ground irradiated bone graft and porous synthetic bone substitute (Apapore 60). J Bone Jt Surg (British) 2010; 92: 617-23.

[22] Shive MS, Hoemann CD, Restrepo A, et al. BST-CarGel: In situ chondroinduction for cartilage repair. Tech Orthop Surg 2006; 16: 271-8.

[23] Choi NY, Kim BW, Yeo WJ, et al. Gel-type autologous chondrocyte (Chondron) implantation for treatment of articular cartilage defects of the knee. BMC Musculoskeletal Disord 2010; 11: 103 .

[24] Dattena M, Pilichi S, Rocca S, et al. Sheep embryonic stem-cells transplanted in full-thickness cartilage defects. J Tissue Eng Regen Med 2009; 3: 175-87.

[25] Bourke SL, Kohn J, Dunn MG. Preliminary development of a novel resorbable synthetic polymer fiber scaffold for anterior cruciate ligament reconstruction. Tissue Eng 2004; 10(1-2): 43-52. 
[26] Cooper JA, Lu HH, Ko FK, Freeman JW, Laurencin CT. Fiberbased tissue-engineered scaffold for ligament replacement: design considerations and in vitro evaluation. Biomaterials 2005; 26(13): 1523-32.

[27] Lu HH, Cooper JA, Jr., Manuel S, et al. Anterior cruciate ligament regeneration using braided biodegradable scaffolds: in vitro optimization studies. Biomaterials 2005; 26(23): 4805-16.

[28] Shao HJ, Chen CS, Lee IC, Wang JH, Young TH. Designing a three-dimensional expanded polytetrafluoroethylene-poly(lactic-coglycolic acid) scaffold for tissue engineering. Artif Organs 2009 Apr; 33(4): 309-17.

[29] Kang SW, Lee SJ, Kim JS, et al. Effect of a Scaffold Fabricated Thermally from Acetylated PLGA on the Formation of Engineered Cartilage. Macromol Biosci 2011; 11(2): 267-74.

[30] Freeman JW, Woods MD, Laurencin CT. Tissue engineering of the anterior cruciate ligament using a braid-twist scaffold design. J Biomech 2007; 40(9): 2029-36.

[31] Freeman JW, Woods MD, Cromer DA, Wright LD, Laurencin CT. Tissue engineering of the anterior cruciate ligament: the viscoelastic behavior and cell viability of a novel braid-twist scaffold. J Biomater Sci Polym Ed 2009; 20(12): 1709-28.

[32] Freeman JW, Woods MD, Cromer DA, et al. Evaluation of a hydrogel-fiber composite for ACL tissue engineering. J Biomech 2011; 44(4): 694-9.

[33] Erggelet C, Kreuz PC, Mrosek EH, et al. Autologous chondrocyte implantation versus ACI using 3D-bioresorbable graft for the treatment of large full-thickness cartilage lesions of the knee. Arch Orthop Trauma Surg 2010; 130: 957-64.

[34] Frisbie DD, Lu Y, Kawcak CE, DiCarlo EF, Binette F, McIlwraith $\mathrm{CW}$. In vivo evaluation of autologous cartilage fragment-loaded scaffolds implanted into equine articular defects and compared with autologous chondrocyte implantation. Am J Sports Med 2009; 37: 71S-80S.

[35] Carmont MR, Carey-Smith R, Saithna A, Dhillon M, Thompson P, Spalding T. Delayed incorporation of a TruFit plug: perseverance is recommended. Arthroscopy 2009; 25: 810-4.

[36] Maher SA, Rodeo SA, Doty SB, et al. Evaluation of a porous polyurethane scaffold in a partial meniscal defect ovine model. Arthroscopy 2010; 26: 1510-9.

[37] Verdonk R, Verdonk P, Huysse W, Forsyth R, Heinrichs EL. Tissue ingrowth after implantation of a novel, biodegradable polyurethane scaffold for treatment of partial meniscal lesions. American Journal of Sports Medicine 2011; 39: 774-82.

[38] Xu C, Su P, Chen X, et al. Biocompatibility and osteogenesis of biomimetic Bioglass-Collagen-Phosphatidylserine composite scaffolds for bone tissue engineering. Biomaterials 2011 Feb; 32(4): 1051-8.

[39] Heymer A, Bradica G, Eulert J, Noth U. Multiphasic collagen fibre-PLA composites seeded with human mesenchymal stem cells for osteochondral defect repair: an in vitro study. J Tissue Eng Regen Med 2009; 3(5): 389-97.

[40] Roohani-Esfahani SI, Nouri-Khorasani S, Lu ZF, Appleyard RC, Zreiqat $H$. Effects of bioactive glass nanoparticles on the mechanical and biological behavior of composite coated scaffolds. Acta Biomater 2011; 7(3): 1307-18.

[41] Shanmugasundaram S, Chaudhry H, Arinzeh TL. Microscale Versus Nanoscale Scaffold Architecture for Mesenchymal Stem Cell Chondrogenesis. Tissue Eng Part A 2010.

[42] Xue Y, Danmark S, Xing Z, et al. Growth and differentiation of bone marrow stromal cells on biodegradable polymer scaffolds: an in vitro study. J Biomed Mater Res A 2010; 95(4): 1244-51.

[43] Rentsch C, Hess R, Rentsch B, et al. Ovine bone marrow mesenchymal stem cells: isolation and characterization of the cells and their osteogenic differentiation potential on embroidered and surface-modified polycaprolactone-co-lactide scaffolds. In Vitro Cell Dev Biol Anim 2010; 46(7): 624-34

[44] Tigli RS, Cannizaro C, Gumusderelioglu M, Kaplan DL. Chondrogenesis in perfusion bioreactors using porous silk scaffolds and hESC-derived MSCs. J Biomed Mater Res A 2011; 96(1): 218 .

[45] Hu J, Feng K, Liu X, Ma PX. Chondrogenic and osteogenic differentiations of human bone marrow-derived mesenchymal stem cells on a nanofibrous scaffold with designed pore network. Biomaterials 2009; 30(28): 5061-7.
[46] Gruber HE, Mauerhan D, Chow Y, et al. Three-dimensional culture of human meniscal cells: extracellular matrix and proteoglycan production. BMC Biotechnol 2008; 8: 54.

[47] Nakata K, Shino K, Hamada M, et al. Human meniscus cell: characterization of the primary culture and use for tissue engineering. Clin Orthop Relat Res 2001; (391 Suppl): S208-18.

[48] Bolgen N, Yang Y, Korkusuz P, Guzel E, El Haj AJ, Piskin E. 3D ingrowth of bovine articular chondrocytes in biodegradable cryogel scaffolds for cartilage tissue engineering. J Tissue Eng Regen Med 2010 [Epub ahead of print].

[49] Zhang L, Spector M. Comparison of three types of chondrocytes in collagen scaffolds for cartilage tissue engineering. Biomed Mater 2009; 4(4): 045012.

[50] Freed LE, Marquis JC, Langer R, Vunjak-Novakovic G. Kinetics of chondrocyte growth in cell-polymer implants. Biotechnol Bioeng 1994; 43(7): 597-604.

[51] Ricci JL, Gona AG, Alexander H. In vitro tendon cell growth rates on a synthetic fiber scaffold material and on standard culture plates. J Biomed Mater Res 1991; 25(5): 651-66.

[52] Ricci JL, Gona AG, Alexander H, Parsons JR. Morphological characteristics of tendon cells cultured on synthetic fibers. J Biomed Mater Res 1984; 18(9): 1073-87.

[53] Di Maggio N, Piccinini E, Jaworski M, Trumpp A, Wendt DJ, Martin I. Toward modeling the bone marrow niche using scaffoldbased 3D culture systems. Biomaterials 2011; 32(2): 321-9.

[54] Han SK, Federico S, Herzog W. A depth-dependent model of the pericellular microenvironment of chondrocytes in articular cartilage. Comput Methods Biomech Biomed Engin 2011; 14(7): 567-9.

[55] Coates EE, Fisher JP. Phenotypic variations in chondrocyte subpopulations and their response to in vitro culture and external stimuli. Ann Biomed Eng 2010; 38(11): 3371-88.

[56] Moffat KL, Wang IN, Rodeo SA, Lu HH. Orthopedic interface tissue engineering for the biological fixation of soft tissue grafts. Clin Sports Med 2009; 28(1): 157-76.

[57] Mandal BB, Park SH, Gil ES, Kaplan DL. Multilayered silk scaffolds for meniscus tissue engineering. Biomaterials 2011; 32(2): 639-51.

[58] Spalazzi JP, Doty SB, Moffat KL, Levine WN, Lu HH. Development of controlled matrix heterogeneity on a triphasic scaffold for orthopedic interface tissue engineering. Tissue Eng 2006; 12(12): 3497-508.

[59] Buschmann J, Welti M, Hemmi S, et al. Three-Dimensional CoCultures of Osteoblasts and Endothelial Cells in DegraPol Foam: Histological and High-Field Magnetic Resonance Imaging Analyses of Pre-Engineered Capillary Networks in Bone Grafts. Tissue Eng Part A 2010.

[60] Spalazzi JP, Dagher E, Doty SB, Guo XE, Rodeo SA, Lu HH. In vivo evaluation of a tri-phasic composite scaffold for anterior cruciate ligament-to-bone integration. Conf Proc IEEE Eng Med Biol Soc 2006; 1: 525-8.

[61] Spalazzi JP, Dagher E, Doty SB, Guo XE, Rodeo SA, Lu HH. In vivo evaluation of a multiphased scaffold designed for orthopaedic interface tissue engineering and soft tissue-to-bone integration. $\mathrm{J}$ Biomed Mater Res A 2008; 86(1): 1-12.

[62] Spalazzi JP, Vyner MC, Jacobs MT, Moffat KL, Lu HH. Mechanoactive scaffold induces tendon remodeling and expression of fibrocartilage markers. Clin Orthop Relat Res 2008; 466(8): 1938-48.

[63] Aigner T, Cook JL, Gerwin N, et al. Histopathology atlas of animal model systems - overview of guiding principles. Osteoarthritis Cartilage 2010; 18(Suppl 3): S2-6.

[64] Magarian EM, Vavken P, Murray MM. Human anterior cruciate ligament fibroblasts from immature patients have a stronger in vitro response to platelet concentrates than those from mature individuals. Knee 2011; 18(4): 247-51.

[65] Tottey S, Johnson SA, Crapo PM, et al. The effect of source animal age upon extracellular matrix scaffold properties. Biomaterials 2011;32(1): 128-36.

[66] Murray MM, Spindler KP, Ballard P, Welch TP, Zurakowski D, Nanney LB. Enhanced histologic repair in a central wound in the anterior cruciate ligament with a collagen-platelet-rich plasma scaffold. J Orthop Res 2007; 25(8): 1007-17.

[67] Hunziker EB, Kapfinger E. Removal of proteoglycans from the surface of defects in articular cartilage transiently enhances coverage by repair cells. J Bone Joint Surg Br 1998; 80(1): 144-50. 
[68] Hunziker EB, Rosenberg LC. Repair of partial thickness defects in articular cartilage: cell recruitment from the synovium. J Bone Joint Surg (American) 1996; 78: 721-33.

[69] Manfredini M, Zerbinati F, Gildone A, Faccini R. Autologous chondrocyte implantation: A comparison between an open periosteal-covered and an arthroscopic matrix-guided technique. Acta Orthopaedica Belgica 2007; 73: 207-18.

[70] Sahoo S, Toh SL, Goh JC. PLGA nanofiber-coated silk microfibrous scaffold for connective tissue engineering. J Biomed Mater Res B Appl Biomater 2010; 95(1): 19-28.

[71] Liang D, Hsiao BS, B C. Functinal electrospun nanofibrous scaffolds for biomedical applications. Adv Drug Deliv Rev 2007; 59: $1392-412$.

[72] Ashammakhi N, Wimpenny I, Nikkola L, Yang Y. Electrospinning: methods and development of biodegradable nanofibres for drug release. J Biomed Nanotechnol 2009; 5(1): 1-19.

[73] Niu X, Feng Q, Wang M, Guo X, Zheng Q. Porous nanoHA/collagen/PLLA scaffold containing chitosan microspheres for controlled delivery of synthetic peptide derived from BMP-2. J Control Release 2009; 134(2): 111-7.

[74] Cao H, Liu T, Chew SY. The application of nanofibrous scaffolds in neural tissue engineering. Adv Drug Deliv Rev 2009; 61(12): 1055-64.

[75] Kim GH. Electrospun PCL nanofibers with anisotropic mechanical properties as a biomedical scaffold. Biomed Mater 2008; 3(2): 025010 .

[76] Lee $\mathrm{CH}$, Shin $\mathrm{HJ}$, Cho $\mathrm{IH}$, et al. Nanofiber alignment and direction of mechanical strain affect the ECM production of human ACL fibroblast. Biomaterials 2005; 26(11): 1261-70.

[77] Jose MV, Thomas V, Xu Y, Bellis S, Nyairo E, Dean D. Aligned bioactive multi-component nanofibrous nanocomposite scaffolds for bone tissue engineering. Macromol Biosci 2010; 10(4): 433-44.
[78] Sahoo S, Toh SL, Goh JC. A bFGF-releasing silk/PLGA-based biohybrid scaffold for ligament/tendon tissue engineering using mesenchymal progenitor cells. Biomaterials 2010; 31(11): 2990-8.

[79] Lee SY, Koak JY, Heo SJ, Kim SK, Lee SJ, Nam SY Osseointegration of anodized titanium implants coated with poly(lactide-co-glycolide)/basic fibroblast growth factor by electrospray. Int J Oral Maxillofac Implants 2010; 25(2): 315-20.

[80] Srouji S, Ben-David D, Lotan R, Livne E, Avrahami R, Zussman E. Slow-Release Human Recombinant Bone Morphogenetic Protein-2 Embedded Within Electrospun Scaffolds for Regeneration of Bone Defect: In Vitro and In Vivo Evaluation. Tissue Eng Part A 2011; 17(3.4): 269-77.

[81] Yilgor P, Sousa RA, Reis RL, Hasirci N, Hasirci V. Effect of scaffold architecture and BMP-2/BMP-7 delivery on in vitro bone regeneration. J Mater Sci Mater Med 2010; 21(11): 2999-3008.

[82] Kamolratanakul P, Hayata T, Ezura Y, et al. Nanogel-based scaffold delivery of prostaglandin $\mathrm{E}_{2}$ receptor-specific agonist in combination with low dosage of growth factor heals critical size bone defect. Arthritis Rheum 2011; 63(4): 1021-33.

[83] Dennes TJ, Hunt GC, Schwarzbauer JE, Schwartz J. High-yield activation of scaffold polymer surfaces to attach cell adhesion molecules. J Am Chem Soc 2007; 129(1): 93-7.

[84] Kisiday J, Jin M, Kurz B, et al. Self-assembling peptide hydrogel fosters chondrocyte extracellular matrix production and cell division: implications for cartilage tissue repair. Proc Natl Acad Sci USA 2002; 99(15): 9996-10001.

[85] Bokhari MA, Akay G, Zhang S, Birch MA. The enhancement of osteoblast growth and differentiation in vitro on a peptide hydrogel-polyHIPE polymer hybrid material. Biomaterials 2005; 26(25): 5198-208.

[86] Horii A, Wang X, Gelain F, Zhang S. Biological designer selfassembling peptide nanofiber scaffolds significantly enhance osteoblast proliferation, differentiation and 3-D migration. PLoS One 2007; 2(2): e190.

(C) Henson and Getgood; Licensee Bentham Open.

This is an open access article licensed under the terms of the Creative Commons Attribution Non-Commercial License (http://creativecommons.org/licenses/by-nc/3.0/) which permits unrestricted, non-commercial use, distribution and reproduction in any medium, provided the work is properly cited. 